\title{
A FAZENDA Escola de FloRestal: APONTAMENTOS SOBRE A INSERÇÃO DE MINAS GERAIS NA MODERNIDADE CAPITALISTA ${ }^{1}$
}

\author{
Daniela Pereira Versieux* \\ danielaversieux@yahoo.com.br
}

Resumo: O presente artigo tem como objeto de estudo a relação da Fazenda Escola de Florestal com o processo de modernização de Minas Gerais. Tal instituição de educação profissional agrícola foi fundada em 1939 e situava-se no então distrito de Florestal, município de Pará de Minas (MG). Ela fez parte do projeto de desenvolvimento econômico executado pelo governo mineiro, que procurava inserir o Estado de Minas Gerais no processo de modernização e racionalização capitalista. O objetivo é explicitar, por meio da Fazenda Escola de Florestal, os nexos entre a política de formação do trabalhador agrícola e o processo de modernização econômica no governo de Benedito Valadares (1933-1945), interventor mineiro nomeado por Getúlio Vargas. Metodologicamente, optou-se por problematizar alguns artigos da Revista da Produção, periódico publicado pelo governo mineiro entre 1937 e 1942.

Palavras-chave: História do ensino agrícola, Modernização, Fazenda Escola de Florestal.

\section{ENSINO AGRÍCOLA E MODERNIZAÇÃO}

O processo de modernização e o de inserção de Minas e do Brasil na modernidade capitalista foram impulsionados com o fim da escravidão e a proclamação da República, em fins do século XIX (DULCI, 2005). Modernidade e modernização têm significações distintas, mas indissociáveis. De acordo com Jean Baudrillard (1977) a modernidade enquanto modo de civilização característico, oposto ao modo da tradição, não tem

* Graduada em Ciências Biológicas pela Universidade Federal de Minas Gerais (UFMG). Especialista em Educação Profissional Técnica Integrada ao Ensino Médio na Modalidade de Educação de Jovens e Adultos (PROEJA, área Educação) pelo Centro Federal de Educação Tecnológica de Minas Gerais - CEFET/MG. Mestre em Educação Tecnológica pelo CEFET/MG. Professora efetiva de Biologia (ensino médio e profissional) da Fundação de Ensino de Contagem (Minas Gerais). 
leis, mas, apesar disso, é possível identificar suas características. Uma delas é ter vínculos profundos com a mudança, com a ruptura e com a descontinuidade e, ao mesmo tempo, afirmar-se na renovação da própria tradição. A modernização articula-se com a modernidade enquanto uma ideologia da mesma, sendo um de seus traços peculiares. Nos países ditos "em desenvolvimento", as contradições da modernidade revelam-se com força brutal, exatamente por se instalar sem um processo de revolução política e industrial, introduzindo somente alguns de seus aspectos, aqueles mais técnicos ou exportáveis (BAUDRILLARD, 1977). Segundo Otávio Dulci (2005), em fins do século XIX,

a abolição do sistema escravista [...] havia removido um grande obstáculo à modernização do país, ensejando a constituição de um efetivo mercado de trabalho e abrindo caminho para a expansão da cidadania, ao igualar juridicamente todos os habitantes sem diferenciá-los pela cor ou por recortes de casta. (DULCI, 2005, p.109).

Nesse momento, ganhou contornos mais nítidos a preocupação com a formação do trabalhador do e para o campo, pois a partir da abolição começaram a faltar braços para a lavoura. Nota-se que a falta era de trabalhadores que quisessem se submeter ao trabalho livre e disciplinado (FURTADO, 2000; WIRTH, 1982). Em São Paulo, a imigração se constituiu enquanto opção principal para suprir a demanda por mão de obra nas plantações de café (HOLANDA, 1995). Em Minas Gerais, debalde as tentativas de atrair os trabalhadores estrangeiros, as classes conservadoras ${ }^{2}$ investiram no aproveitamento do trabalhador nacional (FARIA, 1992; WIRTH, 1982).

A opção pelo trabalhador nacional deu-se, em Minas, no contexto da assunção, pelas elites política, econômica e intelectual, de um projeto de desenvolvimento econômico pautado no "princípio da união na diversidade", que garantiria unidade geográfica e política e evitaria a "perda de substância econômica" ${ }^{3}$ através da "priorização do incremento à agropecuária diversificada” (FARIA, 1992, p.13). Este projeto, explicitado no Congresso Agrícola de $1903^{4}$, constituiu uma alternativa à primazia da agricultura cafeeira, que já nas últimas décadas do século XIX apresentava um acentuado declínio de produtividade e exportações, principalmente nas antigas zonas produtoras de café em Minas - da Mata e Sul; além disso, o projeto cumpriria papel de unificar política e geograficamente o território mineiro, desenvolvendo a "vocação" do Estado para a agricultura de subsistência, com vistas à conquista do mercado nacional (FARIA, 1992; WIRTH, 1982). De acordo com Maria Auxiliadora Faria (1992), 
à concretização desse projeto [de desenvolvimento] se interpunham inúmeros obstáculos, dentre eles, o estrutural, da organização das relações de produção no campo. [...]. Nesse quadro, a defesa e o implemento do ensino agrícola, destinado a crianças e adultos, teria emergido, não apenas como forma inovadora de lidar com a agricultura e a pecuária, mas também como mecanismo de controle social dos trabalhadores, garantindo sua presença no campo e assiduidade ao trabalho. Assim concebido, o ensino agrícola integra o projeto de desenvolvimento econômico mineiro da Primeira República como uma de suas principais metas. (FARIA, 1992, p.13-14 - grifos nossos).

A expressão "ensino agrícola" é aqui compreendida como uma categoria histórica, que expressava um caráter profissional e não era necessariamente vinculada a algum nível de escolaridade. Podia ser um ensino primário-elementar, quando associado à instrução elementar (ler e contar); médio ou técnico, formando agrônomos de nível médio ou técnicos agrícolas; ou ainda ser ministrado em escolas superiores de agricultura, formando agrônomos de nível superior (VERSIEUX, 2010). Em Minas Gerais, a prerrogativa da Secretaria da Agricultura de criar e instalar escolas de ensino agrícola data, pelo menos, da criação deste órgão nos primórdios da República. O decreto estadual n. 588, de 26 de agosto de 1892, que promulgou o regulamento da Secretaria da Agricultura, Comércio e Obras Públicas, encarregou esta pasta, no parágrafo $2^{\circ}$ do seu artigo $5^{\circ}$, do

desenvolvimento dos diversos ramos da indústria e a seu ensino profissional, compreendendo os estabelecimentos industriais e agrícolas, a lavoura e a indústria, a aquisição e distribuição de plantas e sementes; a colocação e exposição de produtos agrícolas industriais, e ao estabelecimento de ensino agrícola e industrial. (MINAS GERAIS, 1893, p. 205).

Porém, o Estado de Minas Gerais suprimiu a Secretaria de Agricultura em 1901, reorganizando-a em 1910 (ANDRADE, 1975), num momento em que há um significativo investimento no ensino agrícola. Faria (1992), compreendendo que a trajetória deste ensino em Minas Gerais na Primeira República iniciou-se ainda no século XIX, segmenta-a em três momentos distintos, nos quais "se superpuseram rupturas e permanências" (FARIA, 1992, p. 309). Presente no discurso e na prática dos primeiros republicanos mineiros, o ensino agrícola enquanto fundamento da política econômica só foi plenamente formulado e implantado a partir do Congresso Agrícola de 1903 e da administração de João Pinheiro da Silva ${ }^{5}$ (FARIA, 1992). 
Até então "apesar da consciência de que o ensino agrícola poderia ser utilizado como dinamizador do desenvolvimento, as tentativas empreendidas foram frustradas, pois de modo geral, o ensino agrícola não saiu da esfera discursiva." (FARIA, 1992). Exceção a este quadro parece ter sido o Instituto Agronômico de Itabira do Mato Dentro, que teve uma existência de 20 anos, desde o final do Império, como Escola Agrícola do Vale do Piracicaba, à primeira década da República (BOTELHO, 2009) e o Jardim Botânico de Ouro Preto, instituição imperial ainda pouco estudada (VERSIEUX, 2010).

No segundo momento, identificado por Faria entre os anos de 1906 e 1916, o ensino agrícola pensado e executado pelo Estado foi fundamentalmente de dois tipos: o primário-elementar e o prático. O primeiro tipo acontecia principalmente nos aprendizados e patronatos agrícolas - sob a alçada do Ministério da Agricultura - e nos institutos agrícolas, sendo o mais representativo da época o Instituto João Pinheiro, inaugurado em 1909, e que funcionou ao lado e conjuntamente com a fazenda-modelo da Gameleira. O ensino agrícola prático, desvinculado de níveis de escolaridade, possuía diversas modalidades e funcionava em diversos estabelecimentos: o ensino ambulante, as fazendas modelo, as fazendas particulares subvencionadas pelo Estado e os campos de demonstração (FARIA, 1992; PRATES, 1911).

A expressão "ensino agrícola prático" foi definida na legislação federal da primeira República como um ensino baseado no trabalho em gabinetes, fazendas experimentais, oficinas, laboratórios e outras instalações similares. Sua parte teórica seria constituída de noções elementares

que possam guiar os alunos na aprendizagem de suas aplicações à agricultura e às indústrias rurais [e] professadas em linguagem simples [...], serão acompanhadas de demonstrações ao alcance dos alunos, de modo a tornar o ensino meramente objetivo (BRASIL, 1910).

Contudo, o ensino agrícola prático ganhou um significado particular, ao menos nas fazendas-modelo de Minas Gerais, que existiram entre 1906 e 1915. Nesses estabelecimentos,

o ensino agrícola "foi ministrado sem aparatosos programas, mas por meio da prática diária e da experiência que cada um adquire na aprendizagem direta dos processos científicos relativos à cultura dos solos e ao preparo dos produtos". E, principalmente, esteve vinculado a uma determinada concepção de progresso e de modernização do Estado, atrelada à produção racional da agricultura (VERSIEUX, 2010, p. 69). 
Esse tipo de ensino tinha como um dos objetivos primordiais acelerar o processo de mecanização do campo. Aqui, é necessário explicitar a relação entre tradição e modernização na agricultura. Os métodos tradicionais da lida com a terra originaram-se em tempos coloniais e tiveram por base a derrubada das florestas, a queimada, o plantio e as colheitas manuais, trabalho este assentado, sobretudo, na mão-de-obra dos negros trazidos da África (FERRARO, 2005). Dessa forma, a modernização da agricultura estava associada, pelo menos desde o final do século XIX e início do século $\mathrm{XX}$, à mecanização das lavouras - a substituição parcial do ser humano por máquinas agrícolas. Porém, as máquinas que se queria introduzir na agricultura, nesse período, ainda eram de tração animal e mesmo de tração humana, como arados, estrumeiras, semeadores, pulverizadores, cultivadores, dentre outras (NOTICIÁRIO, 1906). Elas se constituíam em símbolos da agricultura moderna, em oposição à agricultura tradicional ou extensiva, de tal forma que, em 1915, Raul Soares de Moura, então Secretário da Agricultura, ao avaliar o predomínio da agricultura tradicional no Estado de Minas Gerais, exatamente pela larga utilização do trabalho manual e "passividade diante das vicissitudes da natureza”, idealizava a modernização agrícola, que seria, para ele, uma

fase de industrialização da Agricultura, em que o homem domina inteiramente a produção, a máquina reduz o braço ao mínimo, a irrigação substitui a chuva, os adubos recompõem os elementos da terra, e os métodos científicos de transformação e conservação dos produtos permitem a procura dos melhores mercados (MOURA, 1915, p.33).

Também coexistiram no período o ensino agrícola médio e o superior, porém instituídos pela iniciativa privada e muitas vezes subvencionados pelo Estado. Os exemplos mais significativos foram a Escola Agrícola de Lavras, de nível médio, e a Escola Mineira de Agricultura e Veterinária, de grau superior, que funcionava na Capital. A ausência do Estado na oferta desses níveis de ensino agrícola, aliada à baixa demanda da sociedade, são as razões encontradas por Faria para justificar aí o predomínio das escolas particulares.

A terceira fase do ensino agrícola na Primeira República, de 1916 a 1930, é identificada com o fim das subvenções aos fazendeiros (fazendas subvencionadas, campos de demonstração) e a criação da ESAV - Escola Superior de Agricultura e Veterinária, instituída por lei em 1920 e inaugurada em 1926 no município de Viçosa (MG). "Nesse novo momento, mais 
que instrumento de organização do trabalho no campo, o ensino agrícola foi percebido como meio de modernização da agropecuária... (FARIA, 1992, p. 310). A partir de então, ainda de acordo com Maria Auxiliadora Faria, o Estado passou a investir mais nos níveis secundário e superior, sem abrir mão do ensino agrícola primário.

A Fazenda Escola de Florestal surgiu num contexto em que o ensino agrícola primário e prático já não era há pelo menos uma década prioridade do Estado (VERSIEUX, 2010). Na redefinição político-econômica ocorrida ao final da Primeira República e explicitada durante o Congresso de $1928^{6}$, é significativa a criação e implantação da ESAV, que inaugurou um novo momento no ensino agrícola em Minas Gerais, visto que, sem desconsiderar o ensino primário-elementar e o ensino prático, bem como a necessidade de reorganização do mercado de trabalho e de fixar o trabalhador nacional no campo, deslocou esses eixos para o ensino de caráter teórico-prático, ministrado principalmente nos níveis médio e superior, e para a necessidade da modernização da agricultura diversificada (FARIA, 1992).

Inauguração da Fazenda Escola de Florestal: indícios de sua materialidade E PRÁTICAS PEDAGÓGICAS

A Fazenda Escola de Florestal, inaugurada oficialmente em 26 de abril de 1939, funcionou até 1948, quando foi transformada em EMAF Escola Média de Agricultura de Florestal - e "destinava [-se] à formação de capatazes e administradores de fazenda, além de ministrar cursos rápidos para fazendeiros [...]" (UNIVERSIDADE FEDERAL DE VIÇOSA, 2003), unificando o ambiente de produção agrária com o aprendizado pelo trabalho, através do "aprender-fazendo", na intenção de criar um habitus produtivo, sem afastar o homem do campo do seu meio (REVISTA DA PRODUÇÃO, 1939).

Contudo, a proposta original foi a de criação de uma fazenda modelo em Florestal, estabelecendo campos de culturas experimentais, estábulos de criação de animais para experimentos de melhoramento das raças, bem como usina elétrica, represa, e toda uma série de instalações produtivas. A fazenda modelo de Florestal foi criada para ser

uma fazenda especializada, que servirá de pad[rão] e na qual os fazendeiros poderão aprender a organização geral dos estabelecimentos rurais e as vantagens do sistema das fazendas mistas para o aproveitamento integral dos diversos ramos da produção. (REVISTA DA PRODUÇÃO, 1937, p. 72).

Hist. R., Goiânia, v. 17, n. 2, p. 141-160, jul./dez. 2012 
Este primeiro estabelecimento, a fazenda modelo de Florestal, precursor da Fazenda Escola de Florestal, funcionou pelo menos desde 1936 quando, na previsão orçamentária para esse ano, apareceu pela primeira vez uma dotação de verba específica para a "Fazenda do Florestal” (MINAS GERAIS, 1937). A sua instituição e posterior transformação em Fazenda Escola fez parte do projeto econômico de Benedito Valadares e Israel Pinheiro, do qual além do ensino agrícola, também o integrava a diversificação da agricultura, a propaganda e o desenvolvimento da siderurgia e de várias atividades econômicas do Estado, como o comércio e o turismo ${ }^{7}$.

A inauguração da Fazenda Escola de Florestal, em 1939, foi um evento de grande relevância política para o governo mineiro de Benedito Valadares. O número 16 da Revista da Produção ${ }^{8}$ foi quase totalmente dedicado ao estabelecimento. Desde a capa, os artigos, e até mesmo os anúncios fazem referência a ele. Um dos seus textos chama a atenção para a presença, no evento de inauguração da Fazenda Escola, do "presidente Getúlio Vargas, de altas figuras da administração nacional e do Exército, assim como representantes das classes produtoras" (REVISTA DA PRODUÇÃO, 1939, p. 14). Dentre esses últimos, estavam fazendeiros de todas as regiões do Estado, bem como representantes da indústria e do comércio, sendo o evento transmitido ao vivo pela Rádio Inconfidência, que havia sido criada poucos anos antes.

Acompanhando o passeio do presidente Getúlio Vargas pelas dependências da Fazenda Escola, a revista nos dá uma visão interessante da sua estrutura, finalidades e público-alvo. Ficamos sabendo que a instituição possuía, à época de sua inauguração, estábulos e currais de bovinos para a criação de reprodutores; silos e depósitos de forragens; estrumeiras; bem como "diversas pastagens onde se cultivam os diferentes tipos de forragens, para experiência de resistência e rendimento"; uma "Fábrica Modelo de Laticínios e uma Secção de Máquinas para a preparação de forragem" (REVISTA DA PRODUÇÃO, 1939, p.16). Possuía também plantações e estufas de fumo; currais de gado mestiço, instalações para a criação de patos, marrecos e galinhas; e uma "vasta represa", com uma usina hidroelétrica. Havia ainda campos de cultura, casas residenciais, "onde são alojados os alunos dos Institutos de Assistência à Infância que se destinam ao trabalho agrícola”, pocilgas e baias (REVISTA DA PRODUÇÃO, 1939, p.17).

Toda essa parte, a da "Fazenda", possuía uma administração própria, e foi "organizada nos moldes de um estabelecimento agro-pecuário de exploração econômica e possui todos os requisitos e aperfeiçoamentos técnicos necessários ao seu caráter de fazenda-padrão" (REVISTA DA 
PRODUÇÃO, 1939, p. 22-23). A propriedade destinava-se à criação de vários espécies animais, de interesse comercial, bem como às experiências de cruzamentos e à reprodução de sementes de várias plantas. É explícita a preocupação com a adaptabilidade de animais e plantas ao ambiente brasileiro e à racionalização dos métodos de criação e plantio (REVISTA DA PRODUÇÃO, 1939).

Já a escola, da qual faziam parte um "Hotel dos Fazendeiros" e um internato, além de outras instalações, tinha por finalidades

facilitar a aquisição e aperfeiçoamento de conhecimentos de agricultura e pecuária a todos quantos lidam com a lavoura e a criação, desde o administrador até os simples trabalhadores de fazendas. Só admite como alunos pessoas que já se empreguem nos misteres do campo e sejam enviadas por fazendeiros. É uma escola viva, onde todos os conhecimentos e noções são adquiridos no trabalho e pelo trabalho, fazendo e vendo fazer. (REVISTA DA PRODUÇÃO, 1939, p.23).

Essa passagem nos revela a quem a Fazenda Escola se destinava, pelo menos oficialmente. A partir 1933, de acordo com Sônia Regina Mendonça (2006), vigorou o decreto-lei 23.979, do executivo federal, que transformou os antigos Aprendizados Agrícolas do Ministério da Agricultura, em três tipos de cursos - o Ensino Agrícola, o Ensino Rural e os Cursos de Adaptação. Os dois primeiros destinavam-se a crianças e/ou jovens, já com algum tipo de instrução escolar. Já os Cursos de Adaptação muito se assemelhavam à proposta da Fazenda Escola de Florestal, pois eram

uma inovação quanto ao período anterior [a Primeira República], já que se dirigia não apenas a crianças e adolescentes, mas ao chamado "trabalhador em geral" - adulto, em sua maioria e "sem qualquer diploma ou qualificação profissional prévia". Justamente por isso, os novos Cursos de Adaptação não contavam com calendários formais, organizando-se em qualquer época e tendo como traço principal, posto que voltado ao trabalhador rural adulto e analfabeto, sua rápida duração, estando a matrícula "ao alcance de todos, sem distinção de sexo ou idade" (MENDONÇA, 2006, p.9).

Nos anúncios publicados na Revista da Produção sobre a Fazenda Escola, que visavam divulgá-la aos fazendeiros, temos indicações mais precisas sobre o público desejado pela instituição e pelo governo, e também sobre os tipos de cursos ministrados, que corroboram os achados de Mendonça. Assim versava o anúncio: 
Para formação de trabalhadores rurais e administradores de fazenda, com conhecimentos racionais e práticos de agricultura e pecuária. Curso individual, de uma semana a três meses; curso de três meses e curso de um ano. Para quaisquer empregados de fazendas que sejam encaminhados pelos fazendeiros. Curso de contabilidade agrícola. (REVISTA DA PRODUÇÃO, 1939, contracapa).

Barbosa et all, ao estudarem revistas de divulgação técnico-científica da Escola Superior de Agricultura de Viçosa, publicadas na mesma época em que investigamos, verificaram que os professores dessa instituição percebiam os problemas da agricultura e pecuária mineira organicamente vinculados ao "atraso" do meio rural, e à necessidade de sua modernização. Segundo esses autores, uma das atitudes que revelam as incursões dos professores da ESAV sobre os produtores é a tentativa de difusão de nova mentalidade administrativa:

a falta de utilização de uma contabilidade rural era considerada responsável pelo atraso das unidades produtivas. Tal assertiva é justificada em virtude de uma "averiguação", realizada pelo professor do Departamento de Economia Rural, Erly Dias Brandão (Ceres, ano1, n7, 1940). [...] [Este professor] concluiu que [...] poucas dezenas de produtores haviam declarado possuir algum tipo de controle contábil de seus negócios. Fato que, aos olhos do docente, impossibilitava um domínio seguro acerca dos lucros e prejuízos das propriedades [e que, portanto,] a contabilidade desempenharia papel capital na direção das fazendas uma vez que, em a aprendendo, o agricultor galgaria um passo em direção à posição de "administrador rural". (BARBOSA; BARBOSA, 2006, p. 17, grifos nossos).

Encontramos, pois, nesses autores, uma justificativa para a oferta de um curso de contabilidade agrícola pela Fazenda Escola de Florestal, assim como a formação de administradores das fazendas, que está vinculada à idéia de modernização do campo, através da racionalidade capitalista.

Uma questão recorrente nos artigos da Revista da Produção e que marca o projeto de Fazenda Escola em Florestal é o tipo de aprendizado preconizado para a instituição, que implicou uma determinada concepção da relação entre teoria e prática. Essa concepção, apreendida através dos discursos oficiais, explicitava a importância da aprendizagem pelo trabalho, o "aprender-fazendo", que se expressava não apenas na tentativa de escolarização ${ }^{9}$ dos métodos de trabalho, mas também na forte positividade dada à prática em detrimento da teoria: 
Durante [...] [sua] permanência, o aluno é considerado como empregado da Fazenda, sujeito aos regulamentos e horários dos serviços, e é no correr destes que recebe todas as explicações de que precisar. Quando houver necessidade de explicações de caráter geral ou noções técnicas complementares dos trabalhos práticos, serão ministradas em salas próprias, fora das horas de serviço, terão feição intuitiva e não ultrapassarão ao que for indispensável à compreensão e correta execução dos serviços. (REVISTA DA PRODUÇÃO, 1939, p.23).

Parece-nos que se trata da assunção de uma teoria pedagógica, que identificamos com o escolanovismo, em que estão implícitas relações de poder, perceptíveis por meio da secundarização do conhecimento teórico, restrito a poucos momentos "fora do horário de serviço" e também da negação do conhecimento prático que não estivesse em conformidade com as determinações do fazendeiro, pois a ele caberia escolher o que o "seu" trabalhador deveria aprender. Percebemos uma proximidade com o método intuitivo proclamado e executado na fazenda modelo da Gameleira, no início do século XX. Naquela fazenda, a produção agrícola e pastoril era a forma concreta pela qual se dava a aprendizagem dos métodos de cultivo e criação de animais (VERSIEUX, 2012, p. 39). A autora compreende

o processo de escolarização do trabalho agrícola, entendido aqui como tornar escolar esse tipo de aprendizagem que acontecia tradicionalmente no ambiente de trabalho, como uma face do processo de expropriação que os trabalhadores sofreram na transição do trabalho escrava para o trabalho livre. Expropriação no sentido de destruição de formas mais autônomas de sobrevivência, através da negação da cultura dos trabalhadores, da desvalorização dos seus instrumentos de trabalho tradicionais [...] e dos seus conhecimentos sobre agricultura tradicional. (VERSIEUX, 2012, p. 42).

Os discursos nos revelam ainda o peso da distinção econômica em relação à posse do conhecimento técnico e teórico. Um dos artigos da Revista da Produção expõe a importância e a necessidade da teoria estreitamente relacionada à prática, cuja síntese só poderia ser feita pelos "verdadeiros técnicos", aqueles que saberiam "aliar teoria e prática, idealização e realismo. A teoria orienta, a prática demonstra, a idealização inspira, o realismo executa." (REVISTA DA PRODUÇÃO, 1938, p. 21). Ao ensino superior, primordialmente, e ao ensino técnico, de forma secundária, foi atribuída a prerrogativa de se ensinar a teoria, sempre aliada à prática. E, em relação à agricultura e pecuária, seriam a ESAV e também à Escola de Agronomia e 
Veterinária, situada em Belo Horizonte, as instituições que deveriam colaborar decisivamente na superação do relativo atraso mineiro.

Percebemos, pois, que há uma estreita ligação entre o ensino superior e a Fazenda Escola de Florestal, o segundo como ação política complementar do primeiro. Para os professores da ESAV, "o problema decisivo da estrutura agropecuária se encontrava na persistência da utilização de métodos tradicionais por parte dos agricultores, estes pouco racionais em termos econômicos e produtivos" (BARBOSA; BARBOSA, 2006, p.16). Em outras palavras, a Fazenda Escola de Florestal, juntamente com outras iniciativas, incluindo aí as da própria $\mathrm{ESAV}^{10}$, traria a solução do referido problema, qual seja, o ensinamento de métodos mais adequados à produção capitalista da agricultura, problema este que está intimamente relacionado ao processo de modernização do campo.

A Fazenda Escola de Florestal e o projeto de desenvolvimento eConômico de Benedito Valadares

A Fazenda Escola de Florestal não objetivava apenas "formar e aperfeiçoar administradores e empregados rurais. Ela se destina também, e especialmente, aos fazendeiros, a quem o Governo proporcionará ensejo de um exame, estudo e observação direta de suas atividades" (REVISTA DA PRODUÇÃO, 1939, p.24). Percebemos que os fazendeiros foram o fulcro da preocupação do governo estadual, que a Escola foi concebida para eles: a Secretaria da Agricultura custeava as visitas à Florestal - passe livre nas ferrovias do Estado, hospedagem gratuita por uma semana -; e só poderia estudar quem eles indicassem. O Hotel dos Fazendeiros, já aludido,

hospedará de cada vez algumas dezenas de lavradores e criadores, [...], afim de que, em pleno ambiente rural, sem mudança em seus hábitos, possam viver a vida de uma fazenda-padrão, conhecer e experimentar suas instalações e verificar os resultados da técnica moderna. (REVISTA DA PRODUÇÃO, 1939, p.24).

Indiciariamente percebemos que o governo mineiro pretendeu convencer pela prática as classes produtoras a diversificar e racionalizar a produção, através do aprendizado, pelo fazendeiro, das novas técnicas, ou da demonstração prática da viabilidade e das vantagens em utilizar novas técnicas e instrumentos em suas propriedades, inserindo-os no processo de modernização da economia mineira. Porém, este não era o único intento do executivo estadual. Ao "Hotel dos Fazendeiros" reservava-se o objetivo de 
integrar os produtores rurais, proporcionando uma organicidade maior às classes produtoras, ou até mesmo estimulando a criação de uma consciência de classe entre os proprietários rurais:

Dupla é a função do Hotel dos Fazendeiros: função social, por aproximar e solidarizar elementos sociais que antes se desconheciam, dentro do mesmo meio; função econômica, porque será um centro de observação e estudo, que proporcionará às atividades e iniciativas dos fazendeiros uma orientação certa.

Reunindo-se dezenas de agricultores, procedentes de todas as regiões do Estado, entre eles [...] se formará um nexo de sentimentos, de vontades, no convívio de vários dias, que se evidenciará em aspirações comuns para o desenvolvimento coletivo. Esse intercâmbio (...) inspirará um sentimento de proximidade, de identificação, de comunidade de destinos, dentro dessa grande coletividade que é o povo mineiro. (REVISTA DA PRODUÇÃO, 1939, p.24).

Destacamos também a importância atribuída à relação entre o governo e os fazendeiros. A Revista ressaltava como função "inestimável"

estabelecer relações mais íntimas entre o Governo do Estado e os fazendeiros. [...]. De um lado, os fazendeiros [...] criam o ambiente de confiança e otimismo indispensável à eficiência do seu próprio trabalho e ao pleno desenvolvimento da ação governativa. De outro lado, o Governo ausculta diretamente a opinião dos fazendeiros sobre as atividades agro-pecuárias do Estado; ouve-os a respeito da vida rural e seus problemas; [...]. Desse modo, a Fazenda torna os fazendeiros colaboradores da ação administrativa, interessando-os diretamente na execução do programa econômico do Governo. (REVISTA DA PRODUÇÃO, 1939, p. 24).

Este trecho nos faz pensar sobre a necessidade de sustentação política do Governo de Benedito Valadares. Por um lado, o interventor mineiro, já à frente do executivo há mais de cinco anos, o foi por apenas dois anos como governador constitucional, tendo sido durante todo o restante do período interventor nomeado pelo Presidente Getúlio Vargas. À época da sua primeira nomeação como interventor, era um político obscuro e sem bases eleitorais, o que provocou a indignação dos que cobiçavam o cargo. Por outro lado, seu plano de desenvolvimento baseava-se fundamentalmente na idéia de diversificação das atividades agrárias e demais atividades econômicas, desatrelando a economia mineira da dependência do café, já 
em sua segunda crise profunda há pelo menos uma década. Para isso, pois, dependia da adesão das classes produtoras mineiras.

Assim, não foi a retenção do homem do campo em seu meio o único objetivo proposto à Fazenda Escola. É necessário considerar que

o Governo Valadares será importante centro aglutinador do corpo técnico mineiro, será relevante no que concerne à propulsão de políticas públicas desenvolvimentistas, além de, inclusive, ser fundamental na centralização das elites regionais em torno do Estado (BARBOSA; BARBOSA, 2006, p. 3).

E, nesse sentido, a Fazenda Escola de Florestal, ao compor seu projeto econômico, contribuía com a modernização da

técnica do trabalho agrícola, visando ao rendimento do esforço humano, o que só se obtém pelo emprego da máquina, que multiplica a eficiência do trabalho no tempo e na economia. (REVISTA DA PRODUÇÃO, 1939, p. 11).

É importante ressaltar a atuação das classes produtoras, depois de 1930, no sentido de interferir direta ou indiretamente no mercado de trabalho. Todavia, a percepção do trabalho ou do mercado de trabalho era substantivamente mais abrangente do que no início do século. [...] No âmbito da formação técnica e profissional, [...], o que se exigiu do poder público foi ação direta no sentido de criação e reorganização de estabelecimentos que formassem profissionalmente "um novo homem", apto a ingressar no mercado de trabalho da cidade e do campo, merecendo destaque especial as "fábricas escolas" e a Fazenda Escola de Florestal, fundada em 1938 [...]. (FARIA, 1992, p. 215).

\section{CONSIDERAÇõES FINAIS}

A despeito da opinião oficial, divulgada por meio da Revista da Produção que, quando da inauguração da Fazenda Escola, chamou atenção para o "caráter inédito da instituição idealizada e criada pelo Governo Mineiro" (MINAS GERAIS, 1939, p.4), depreende-se da literatura que a idéia de unificar o ambiente da fazenda com o aprendizado escolar, escolarizando os saberes da faina agrícola, foi sendo gestada ao longo dos séculos XIX e XX (VERSIEUX, 2010; FARIA, 1992). 
Em Minas Gerais, esse projeto ganhou concretude com as fazendas modelo de João Pinheiro (VERSIEUX, 2010) e foi retomado, quase 30 anos depois - em outro contexto -, pelo governo de Benedito Valadares e Israel Pinheiro, através da Secretaria da Agricultura. O entrecruzando da cultura política, da história econômica de Minas Gerais e da história da educação profissional agrícola por meio da criação e implantação da Fazenda Escola de Florestal aponta para certa continuidade de projetos para a formação do trabalhador do campo.

Otávio Dulci (2005) já indicava algumas vinculações entre os projetos ou modelos de desenvolvimento econômico de João Pinheiro da Silva (1906-1908) e Valadares/Israel Pinheiro (1937-1942). Este autor salienta diversos pontos de convergência e de divergência entre esses modelos, dos quais destaco a aposta, comum a ambos, na diversificação na produção econômica, precedida por crises da cafeicultura. As políticas econômicas dos dois períodos foram semelhantes

sobretudo no que diz respeito à idéia de uma substituição evolutiva de importações que, a partir da agricultura, se estendesse gradativamente para o setor industrial até alcançar os ramos tecnologicamente mais complexos. O incremento da agroindústria, em que eles apostaram com vigor, obedecia a essa lógica. Outra semelhança era a destinação prioritária de recursos governamentais a ramos novos ou pelo menos não-tradicionais. Também João Pinheiro havia insistido na introdução de novas culturas e na necessidade do investimento público para viabilizá-las. E, por fim, houve certa analogia quanto aos resultados, que foram concretos, mas não corresponderam às expectativas entusiásticas das autoridades. (DULCI, 2005, p. 132-133).

Ressaltamos ainda o parentesco entre Israel e João Pinheiro, bem como a referência que o primeiro tinha no segundo (GUIMARÃES, 1990; GOMES, 2005); a proximidade pedagógica entre os dois projetos, com ênfase no ensino prático e intuitivo (VERSIEUX, 2012); e, de acordo com John Wirth (1982), a continuidade como característica da política em Minas Gerais em detrimento da mudança.

O ensino agrícola fez parte dos projetos de desenvolvimento econômico de Minas Gerais tanto na primeira República quanto na fase posterior, convivendo no governo de Benedito Valadares com a política de desenvolvimento industrial e diversificação econômica. Contudo, tal ensino atendeu a objetivos diferentes, sendo essencialmente distinto em cada momento em que foi proposto e executado. No início do século XX a preocupação 
era com a ausência de trabalhadores rurais dispostos a vender sua força de trabalho, como já foi salientado. Em fins da década de 1930, uma questão já se colocava no cenário político e econômico: o êxodo rural e a necessidade de reter o trabalhador no campo. Além disso destacamos: o papel de sustentação política do interventor Benedito Valadares entre as chamadas classes produtoras e a necessidade econômica de substituir trabalhadores do campo por máquinas agrícolas, formando trabalhadores aptos a realizarem a transição da agricultura extensiva para a agricultura intensiva, aprofundando o processo de modernização no meio rural.

\section{The Florestal School Farm: notes on insertion of Minas Gerais in capitalist MODERNITY}

Aвstract: This paper has as a research object the "Florestal School Farm", an agricultural vocational education institution founded in 1939 and located in the city of Florestal, Minas Gerais. The aim is to understand how the "School Farm of Florestal" was part of the economic development project run by the state government that sought to insert Minas Gerais in the process of capitalist modernization and rationalization. Methodologically, it was decided to discuss some articles of the "Revista da Produção", a magazine published by the government of Minas Gerais between 1937 and 1942 .

Key Words: Agricultural schooling history, Modernization, School farm of Florestal.

\section{NOTAS}

1 Este artigo foi apresentado originalmente sob a forma de comunicação oral no V Congresso de Pesquisa e Ensino de História da Educação em Minas Gerais, ocorrido na cidade de Montes Claros entre os dias 5 e 7 de maio de 2009. Vai aqui com algumas modificações e atualizações realizadas a partir da pesquisa de mestrado concluída pela autora em 2010 (VERSIEUX, 2010).

2 Maria Auxiliadora Faria considera a expressão "classes conservadoras" como uma categoria historicamente constituída, justificando o seu uso pela freqüência com que aparece nos documentos referentes à Primeira República em Minas Gerais, na qual as classes conservadoras não encerravam "apenas os interesses da agro-exportação [...] significava[m], [...], o conjunto dos agricultores, comerciantes, dos industriais, dos banqueiros e de todos aqueles que, de uma forma ou de outra, se ligavam ao mundo da produção. A abrangência do termo perpassou o momento crucial de consolidação do novo regime e foi usada por seus representantes até mesmo no pós-30.” (FARIA, 1992, p.35). Faria (1992) usa como sinônimo a expressão "classes produtoras". 
3 Esta expressão, recorrente à época, traduzia a percepção das classes conservadoras mineiras do relativo atraso econômico do Estado. Atraso esse percebido em contraste com o passado de riqueza, advinda do ciclo da mineração do ouro, e também das comparações entre o desenvolvimento mineiro e o de São Paulo, sobretudo. Esse diagnóstico era talvez exagerado, pois a economia mineira apresentou um crescimento, embora em ritmo lento, durante todo o século XIX (DULCI, 2005; WIRTH, 1982).

4 Congresso Agrícola, Comercial e Industrial ocorrido entre 13 e 19 de maio de 1903, em Belo Horizonte, que reuniu, pela primeira vez, figuras expressivas da política e da economia mineira - as classes produtoras e a elite intelectual. Patrocinado pelo governo de Francisco Salles, foi organizado, presidido e liderado por João Pinheiro da Silva, realizando um rigoroso diagnóstico da então realidade regional e nacional, a partir do qual foi traçado um projeto de desenvolvimento econômico para o Estado (FARIA, 1992; DULCI, 2005).

5 João Pinheiro da Silva foi bacharel, político e industrial. Republicano histórico, exerceu a chefia do executivo mineiro por duas vezes - em 1890, como Governador, e entre 1906 e 1908, como Presidente do Estado. (BARBOSA, 1980). Nesta passagem do texto, refiro-me especificamente ao segundo mandato de Pinheiro.

6 Congresso Comercial, Industrial e Agrícola, realizado em Belo Horizonte, em 1928, sob convocação das Associações Comerciais de Minas e de Juiz de Fora e pelo Centro Industrial de Juiz de Fora. As classes conservadoras apontaram nessa ocasião, "para a necessidade de um programa mais amplo, menos agrarista que o proposto em 1903" (FARIA, 1992, p. 206) em que as teses "expressavam a necessidade de racionalização da economia e a minimização dos problemas sociais advindos do desenvolvimento" (FARIA, 1992, p. 209).

7 O governo de Benedito Valadares (1933-1945), "representou a política de interventoria regional organizada por Vargas a partir de 1930. No caso mineiro, em específico, Valadares somente assume em 1933 devido à morte de Olegário Maciel, que embora não fosse interventor, era apoiador de Vargas, logo, não sendo substituído de imediato com o advento revolucionário de 1930." (BARBOSA; BARBOSA, 2006, p. 3). Israel Pinheiro, filho de João Pinheiro da Silva, foi seu secretário desde 1933 até 1942, quando foi chamado a criar a Companhia Vale do Rio Doce.

8 Esta revista foi editada e veiculada pela Secretaria da Agricultura, Indústria, Comércio e Trabalho de Minas Gerais e circulou entre os anos de 1937 e 1942. Fez parte do projeto de desenvolvimento do Estado de Minas Gerais, enquanto meio de divulgação da política de Benedito Valadares e Israel Pinheiro. Voltada para um público diversificado, mas de certa erudição, seus artigos eram de interesse das classes produtoras mineiras, particularmente os proprietários de terras e fazendas, organicamente vinculados à produção agrícola e pecuária do 
Estado de Minas Gerais, bem como os industriais do setor de extração mineral e de outros setores menos significativos da economia mineira.

9 Faria Filho utiliza este conceito a partir de três sentidos: "Num primeiro, escolarização pretende designar o estabelecimento de processos e políticas concernentes à "organização" de uma rede, ou redes, de instituições, mais ou menos formais, responsáveis, seja pelo ensino elementar da leitura, da escrita, do cálculo e, o mais das vezes, da moral e da religião, seja pelo atendimento em níveis posteriores e mais aprofundados." E aqui incluímos a rede de ensino agrícola que veio se formando em Minas Gerais pelo menos desde 1906. "Em outra acepção, estamos entendendo por escolarização o processo e a paulatina produção de referências sociais tendo a escola, ou a forma escolar de socialização e transmissão de conhecimentos, como eixo articulador de seus sentidos e significados. Neste caso, nossa atenção estará voltada para o que temos chamado de "conseqüências" sociais, culturais e políticas da escolarização" (FARIA FILHO, 2002, p.16). O autor chama atenção ainda para a relação entre o processo de escolarização e a produção e fortalecimento do Estado Nacional (FARIA FILHO, 2002). Finalmente, o autor entende o processo de escolarização como o ato ou efeito de tornar escolar, ou seja, "o processo de submetimento de pessoas, conhecimentos, sensibilidades e valores aos imperativos escolares" (FARIA FILHO, 2007, p. 195).

10 A própria ESAV já promovia cursos rápidos para administradores de fazendas, atividades de extensão rural e, desde 1929, a "Semana do Fazendeiro", evento que se realiza ainda nos dias de hoje.

\section{RefERÊNCIAS}

Andrade, Francisco de Assis. Relação dos Chefes do Governo Mineiro e seus Secretários: 1894 a 31 de dezembro de 1974. Revista do Arquivo Público Mineiro. Belo Horizonte, volume 26, p. 7-62, maio de 1975. Disponível em: <http://www. siaapm.cultura.mg.gov.br/modules/rapm/brtacervo.php?cid=856\&op=1>. Acesso em: 16 de maio de 2012.

Barbosa, Francisco de Assis (org.). As Idéias Políticas de João Pinheiro: cronologia, introdução, notas bibliográficas e textos selecionados. Brasília: Senado Federal/MEC; Rio de Janeiro: Fundação Rui Barbosa, 1980. 415p. (Coleção Ação e Pensamento da República).

Barbosa, Lidiany Silva; Barbosa, Daniel Henrique Diniz. Engenheiros mineiros na era Vargas: uma contribuição sobre a atuação do corpo técnico, as políticas públicas e o processo de desenvolvimento de Minas Gerais. In: SEMINÁrio sobre a ECONOMIA MINEIRA: ECONOMIA, HISTÓRIA, DEMOGRAFIA E POLÍTICAS PÚBLICAS, 12, 2006, Diamantina. Anais eletrônicos do XII Seminário sobre a Economia Mineira: Economia, História, Demografia e políticas públicas, 2006. Disponível em: <http:// 
www.cedeplar.ufmg.br/seminarios/seminario_diamantina/2006/D06A069.pdf>. Acesso em: 16 de maio de 2012.

Baudrillard, Jean. Modernité. In: ENCICLOPÆDIA Universalis. Vol. 11. Paris, 1977. p.139-141.

Botelho, Jorge Florentino. A formação do trabalhador do campo em Minas Gerais: o Instituto Agronômico de Itabira (1880-1898). 2009. 120 f. (Dissertação de Mestrado, Educação Tecnológica). Centro Federal de Educação Tecnológica de Minas Gerais, Belo Horizonte, 2009.

BRASIL. Decreto 8319, de 20 de outubro de 1910. Cria o ensino agronômico e aprova o respectivo regulamento. Coleção de Leis do Brasil, 1910. Senado Federal, Brasília, DF. Disponível em: <http://www6.senado.gov.br/legislacao/ListaPublicacoes. action?id=58189>. Acesso em: 16 de maio de 2012.

Dulci, Otávio. João Pinheiro e as origens do desenvolvimento mineiro. In: Gomes, Ângela de Castro (org.). Minas e os fundamentos do Brasil Moderno. Belo Horizonte: Editora UFMG/Humanitas, 2005. Cap. III, p. 109-136.

FARIA, Maria Auxiliadora. A Política da Gleba: As Classes Conservadoras Mineiras; discurso e prática na Primeira República. 1992. 394 f. (Tese de Doutorado, História Social). Faculdade de Filosofia, Letras e Ciências Humanas, Universidade de São Paulo, 1992.

FARIA FilHo, Luciano Mendes de. Escolarização e cultura escolar no Brasil: reflexões em torno de alguns pressupostos e desafios. In: BencostTA, Marcus Levy Alvino (org.). Culturas escolares, saberes e práticas educativas: itinerários históricos. São Paulo: Cortez, 2007. p. 193-211.

FARIA FilHo, Luciano Mendes de. Escolarização, culturas e práticas escolares no Brasil: elementos teórico-metodológicos de um programa de pesquisa. In: Lopes, Alice Casimiro; MAcedo, Elizabeth (orgs.). Disciplinas e integração curricular: história e políticas. Rio de Janeiro: DP\&A, 2002. p. 13-35.

Ferraro, Mário Roberto. A gênese da agricultura e da silvicultura moderna no Estado de São Paulo. 2005. 106f. (Dissertação de Mestrado, Recursos Florestais, Conservação de Ecossistemas Florestais). Escola Superior de Agricultura Luiz de Queiroz, Universidade de São Paulo, Piracicaba, 2005.

Furtado, 2000. Formação Econômica do Brasil. 27a edição. São Paulo: Companhia Editora Nacional: Publifolha, 2000. (Coleção Grandes Nomes do Pensamento Brasileiro). 276p.

Gomes, Ângela de Castro. Memória, política e tradição familiar: os Pinheiro das Minas Gerais. In: Gomes, Ângela de Castro (org.). Minas e os fundamentos do Brasil moderno. Belo Horizonte: Editora UFMG, 2005. p. 79-108.

Guimarães, Anchieta. Secretários da Agricultura de 1933 a 1988: esboço histórico administrativo. Belo Horizonte: Imprensa Oficial, 1990. Vol. I, 454p. 
Holanda, Sérgio Buarque de. Raízes do Brasil. 26 ed. São Paulo: Companhia das Letras, 1995. 220p.

MendonçA, Sonia Regina de. Estado e ensino agrícola no Brasil: da dimensão escolar ao extensionismo-assistencialismo (1930-1950). In: Congreso Latinoamericano de Sociología Rural, 7, 2006, Quito. Anais do VII Congreso Latinoamericano de Sociología Rural. Quito: ALASRU-FLACSO, 2006. p. 01-10.

Minas Gerais. Decreto n. 588, de 26 de Agosto de 1892. Promulga o regulamento da Secretaria da Agricultura, Comércio e Obras Públicas. Coleção de Leis e Decretos do Estado de Minas Gerais em 1892. Ouro Preto, Imprensa Oficial de Minas Gerais, p. 203-242, 1893.

Minas Gerais. Tabelas explicativas do orçamento para o exercício de 1936. Lei N. 15. Orça a receita e fixa a despesa para o exercício de 1936. Coleção das Leis e Decretos de 1935, Belo Horizonte, Imprensa Oficial do Estado, p.48-202, 1937.

Moura, Raul Soares. Relatório apresentado ao Exmo. Sr. Delfim Moreira Da Costa Ribeiro, Presidente do Estado De Minas, pelo Dr. Raul Soares de Moura, Secretário da Agricultura, Indústria, Terras, Viação e Obras Públicas no ano de 1915. $1^{\circ}$ vol. Belo Horizonte, Imprensa Oficial do Estado de Minas Gerais, 1915. 110p.

Noticiário. Revista de Minas: Comércio, Indústria e Lavoura. Belo Horizonte, $\mathrm{n}$. 1, p. 7, 15 de março de 1906.

Prates, Carlos. Ensino agrícola e profissional. In: Prates, Carlos. Relatório apresentado ao Exmo. Sr. Dr. José Gonçalves de Sousa, Secretario da Agricultura, pelo Engenheiro Carlos Prates, Diretor de Agricultura, Terras e Colonização, referente ao ano de 1910. Belo Horizonte: Imprensa Oficial do Estado de Minas Gerais, 1911. Relatório.

Revista da Produção. Belo Horizonte: Secretaria da Agricultura, Indústria, Comércio e Trabalho de Minas Gerais, nºs. 4, 5 e 6, ano 1, jun./jul./ago. 1937.

Revista da Produção. Belo Horizonte: Secretaria da Agricultura, Indústria, Comércio e Trabalho de Minas Gerais, n. 11, ano 2, jan. 1938.

Revista da Produção. Belo Horizonte: Secretaria da Agricultura, Indústria, Comércio e Trabalho de Minas Gerais, n. 16, ano 3, mai./jun. 1939.

Universidade Federal de Viçosa. Conselho Universitário. Resolução n. 9/2003, de 26 de setembro de 2003. Aprova o Regimento da Central de Ensino e Desenvolvimento Agrário de Florestal - CEDAF. Viçosa: Universidade Federal de Viçosa, 2003. Disponível em: <http://www.ufv.br/soc/files/pag/consu/completa/2003/03_09.htm> Acesso em: 16 de maio de 2012.

Versieux, Daniela Pereira. Educação profissional agrícola em Minas Gerais no início do século XX e o ensino de adultos pelo método intuitivo. Boletim Técnico do SENAC: a revista da educação profissional. Rio de Janeiro, v. $38, \mathrm{n}^{\circ}$ 1, jan./abr. 2012. 
Versieux, Daniela Pereira. Modernização e escolarização do trabalho agrícola: as fazendas-modelo em Minas Gerais (1906-1915). 2010. 232f. (Dissertação de mestrado, Educação Tecnológica). Centro Federal de Educação Tecnológica de Minas Gerais: Belo Horizonte, 2010.

Wirth, John D. O Fiel da Balança: Minas Gerais na Federação Brasileira (1889-1937). Tradução de Maria Carmelita Pádua Dias. Rio de Janeiro: Paz e Terra, 1982. 384p. 